\title{
Long Duration Hot Hydrogen Exposure of Nuclear Thermal Rocket Materials
}

\author{
Ron J. Litchford ${ }^{1}$, John P. Foote ${ }^{2}$, Robert Hickman ${ }^{3}$ \\ Chris Dobson ${ }^{4}$, and Scooter Clifton ${ }^{5}$ \\ NASA Marshall Space Flight Center
}

\begin{abstract}
An arc-heater driven hyper-thermal convective environments simulator was recently developed and commissioned for long duration hot hydrogen exposure of nuclear thermal rocket materials. This newly established non-nuclear testing capability uses a high-power, multi-gas, wall-stabilized constricted arc-heater to produce high-temperature pressurized hydrogen flows representative of nuclear reactor core environments, excepting radiation effects, and is intended to serve as a low cost test facility for the purpose of investigating and characterizing candidate fuel/structural materials and improving associated processing/fabrication techniques. Design and engineering development efforts are fully summarized, and facility operating characteristics are reported as determined from a series of baseline performance mapping runs and long duration capability demonstration tests.
\end{abstract}

\section{Introduction}

$\mathrm{N}$ UCLEAR thermal propulsion is often suggested as a component of future space transportation architectures because of the potential performance gains over chemical propulsion systems, whose energy content is physically limited by molecular bond strengths. In principle, high-thrust nuclear thermal rockets (NTR) using pure hydrogen propellant could produce twice the specific impulse of chemical rockets and could therefore greatly expand lunar exploration capability and reduce the duration of crewed Mars expeditions to a biologically manageable level. However, previous NTR development efforts have revealed that it is exceedingly difficult to attain this level of performance in practice due to the fundamental material issues and engineering constraints encountered in high-temperature hydrogen environments. The principle design dilemma derives from the need to maximize performance by increasing fuel operating temperature whereas engine durability and reliability is critically dependent on the ability of the fuel element and thrust chamber materials to withstand severe chemical attack by high-pressure hot hydrogen flow.

Although most space missions of interest would at most require only a few hours of solid-core NTR operation, the desire to push fuel element temperatures to extremes in order to maximize performance greatly intensifies hydrogen induced corrosion rates, which are known to increase in direct proportion to reactor operating temperature. As a result, design closure becomes problematic, and the maximum fuel operating temperature must reflect a balance between competing engineering interests, as illustrated on a typical NTR pressure-temperature operating map in Fig. 1. The critical technical obstacle to a practically useful NTR engine; therefore, is the development of innovative high-temperature fuel/structural materials that can endure $2500-3000 \mathrm{~K}$ hydrogen environments with minimal corrosion under pressures in excess of $3 \mathrm{MPa}$ while also possessing sufficient strength and resilience to resist breakage from intense vibration loads and thermally induced stresses. Moreover, the need to optimize propulsion system power density invariably leads to extremely high radiation flux operating conditions, which introduces significant additional design complexities related to reactor core materials.

\footnotetext{
${ }^{1}$ Project Principal Investigator, Thermal/Combustion Devices, Propulsion System Dept., Associate Fellow AIAA.

${ }^{2}$ Project Engineer (Jacobs/Sverdrup), Thermal/Combustion Devices, Propulsion Systems Dept.

${ }^{3}$ Project Materials Engineer, Structural Materials, Materials and Processes Laboratory.

${ }^{4}$ Project Physicist, Thermal Analysis, Propulsion Systems Dept.

${ }^{5}$ Facility Engineer (Lockheed-Martin Corp.), Materials Environment Test Complex (METCO).
} 
During the ROVER/NERVA program, considerable progress was made in reactor fuel development yielding a viable technology base of continuing relevance to space exploration needs. ${ }^{[1-6]}$ Through a development cycle extending over numerous hot reactor tests, this national program arrived at coated graphite-based fuel formulations exhibiting good structural integrity and low corrosion rates under sustained high temperature operation (in excess of $2200 \mathrm{~K}$ for more than 1 hour). Parallel efforts in the former USSR focusing principally on refractory carbide fuel development reported similarly promising results. ${ }^{[7]}$ These significant achievements still fall far short of ultimate material limits, however, and substantial potential exists for further improvement. Moreover, the significant work accomplished within these programs is decades old and the resulting knowledge, although summarized in various reports, was never completely encapsulated and transferred to modern generations.

In view of the limited knowledge on phase relationships and stability of these carbon systems as well as the significant advances in high temperature fuel formulations and processing over the intervening years, it is therefore important that reactor fuel technology be revisited and thoroughly re-examined prior to embarking on a modern NTR engine development path. Promising contemporary approaches for realizing additional extensions in operating temperature and lifetime include utilization of modern coating techniques and advanced high-temperature materials such as bi/tri-carbides of the U-Zr-X type, carbon-nitrides of $\mathrm{U}$ and $\mathrm{Zr}$, and CERMETs based on a $\mathrm{W}$ matrix.

For structural component applications, it would also be desirable to develop a more thorough understanding of refractory metals and their alloys, such as W, Re, W-Re, Mo, Mo-Re, and W-Re-Hfc, because of their high melting temperatures and inherent resistance to hot hydrogen. The application potential of refractory metals is normally constrained, since they usually must be forged to obtain adequate properties and because they suffer from poor ductility and reduced strength at elevated temperatures. Forging refractory metals into complex shapes, however, is difficult and expensive, and several new forming processes have been developed in recent years to overcome these limitations. Some recent innovations relevant to NTR needs include the Vacuum Plasma Spray (VPS) and Electroforming (El-Form) processes, which were developed for fabricating low cost, net shape refractory metal components such as boost and tactical motor nozzles.

Practical development and characterization of these advanced fuel/structural materials would greatly benefit from low-cost non-nuclear test and evaluation methods in which material samples could undergo long duration exposure to severely corrosive hot hydrogen environments with temperatures ranging as high as $3000 \mathrm{~K}$. Due to the hazards associated with hot hydrogen and the limited scope of utilization, laboratory facilities for this type of R\&D work are not generally available and special efforts are needed to develop and establish this class of non nuclear test capability. This paper describes the development of an NTR environments simulator based on a high-power multigas arc-heater thermal source, which was commissioned for the purpose of partially satisfying this critical need.

\section{Technical Approach}

Most technical specialist tend to view non-nuclear fuels testing as being deficient in several respects, mainly because of the inability to account for radiation effects which are know to have a significant influence on the corrosive action of hydrogen ${ }^{[8,9]}$ It is our contention, however, that the principal physicochemical processes can be effectively addressed using non-nuclear test and evaluation methods. By cleverly designing ohmic-type experimental apparatus, for instance, we suggest that considerable understanding, knowledge, and technical progress could be realized as an interim step in the overall technology development process. Such approaches would greatly reduce the complexity and cost of upfront high temperature fuel $R \& D$ and should be viewed as welcome additions to the inventory of test and evaluation capabilities supporting NTR engine development. 


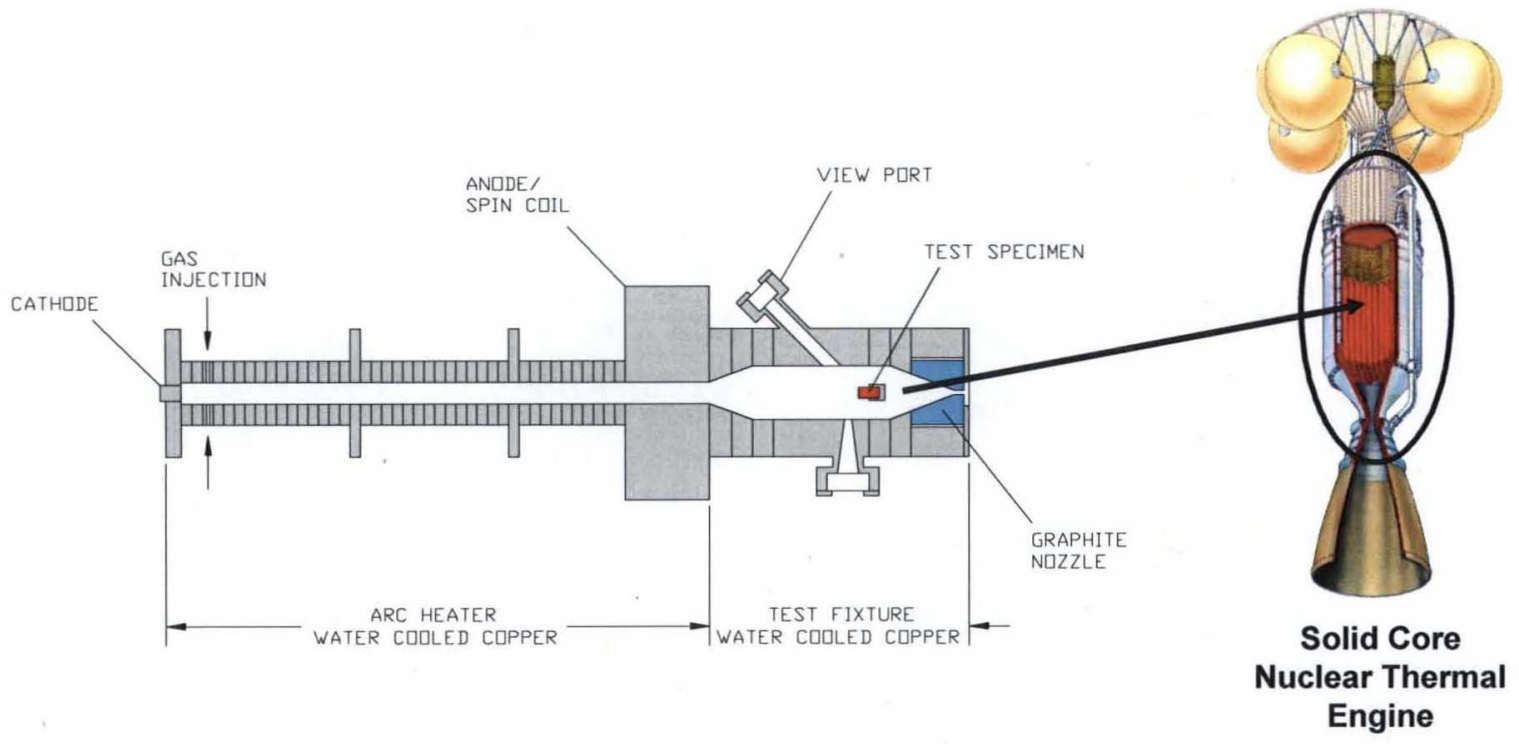

Figure 2. Baseline configuration of arc-heater driven nuclear thermal rocket environment simulator for the generation of hyper-thermal convective conditions traceable to reactor core environments

As an initial step toward the establishment of a full range of non-nuclear testing capabilities, it was considered desirable to first establish a rudimentary facility for exposing reactor material specimens to flowing hot hydrogen. The approach here was to adapt an existing high-power multi-gas arc-heater facility for hydrogen operation and to develop an attachable test fixture for exposing small material specimens to a simulated reactor environment, as illustrated in Fig. 2. The purpose of this baseline test capability is to enable rapid screening and assessment of candidate material specimens, at relatively low cost, and to identify those methods worthy of more in-depth study and systematic development. The basic idea is to produce small, easily fabricated material specimens using innovative processing and manufacturing techniques and to expose these specimens to relevant hot hydrogen environments, excluding radiation effects. Materials and processing techniques could then be perfected by following an iterative approach whereby understanding and knowledge gained from post-test analysis and inspections of exposed specimens are used to validate physics based modeling efforts and to improve fabrication/processing techniques. It is believed that this type of non-nuclear approach will be the most cost effective strategy for arriving at optimal material candidates for actual nuclear environments testing, which can be orders of magnitude more expensive to conduct. A peripheral but important secondary objective is the detailed measurement of hot hydrogen thermodynamic properties and their effect on hydrogen engine performance since available data are not firmly anchored to reliable empirical measurements in the temperature regime of interest. The technological knowledge base established through such efforts would represent a valuable contribution to long term space exploration goals and would provide a solid foundation for future development of an NTR flight engine.

\section{Facility Development}

\section{A. Arc-Heater Description}

The hyper-thermal conditions for simulation of NTR reactor core environments are generated by a $1-\mathrm{MW}_{\mathrm{e}}$ (nominal) multi-gas segmented arc-heater, which operates in a wall-stabilized constricted arc DC discharge mode. This device was originally developed by Aerotherm Corporation in Mountain View, CA more than 30 years ago, but was decommissioned and transferred to Marshall Space Flight Center (MSFC) in 1998 with the intent of supporting propulsion materials development and qualification testing, primarily solid motor nozzle materials. The system was never fully utilized as projected, however, and has therefore been generally available to support other R\&D test programs, including nuclear thermal propulsion technology development efforts.

This particular arc-heater has a 1-inch internal bore diameter and follows the traditional segmentation design philosophy whereby alternating conductor/insulator wafers are stacked together to form the full length assembly, as illustrated in Fig. 3. The 3/8-inch thick heat conducting copper segments are water cooled and are separated by boron nitride insulators in stacked pack subassemblies, which are held securely together by four inconel tie rods. These subassembly packs are then attached in a sequential manner to form the full arc-heater column, which spans 

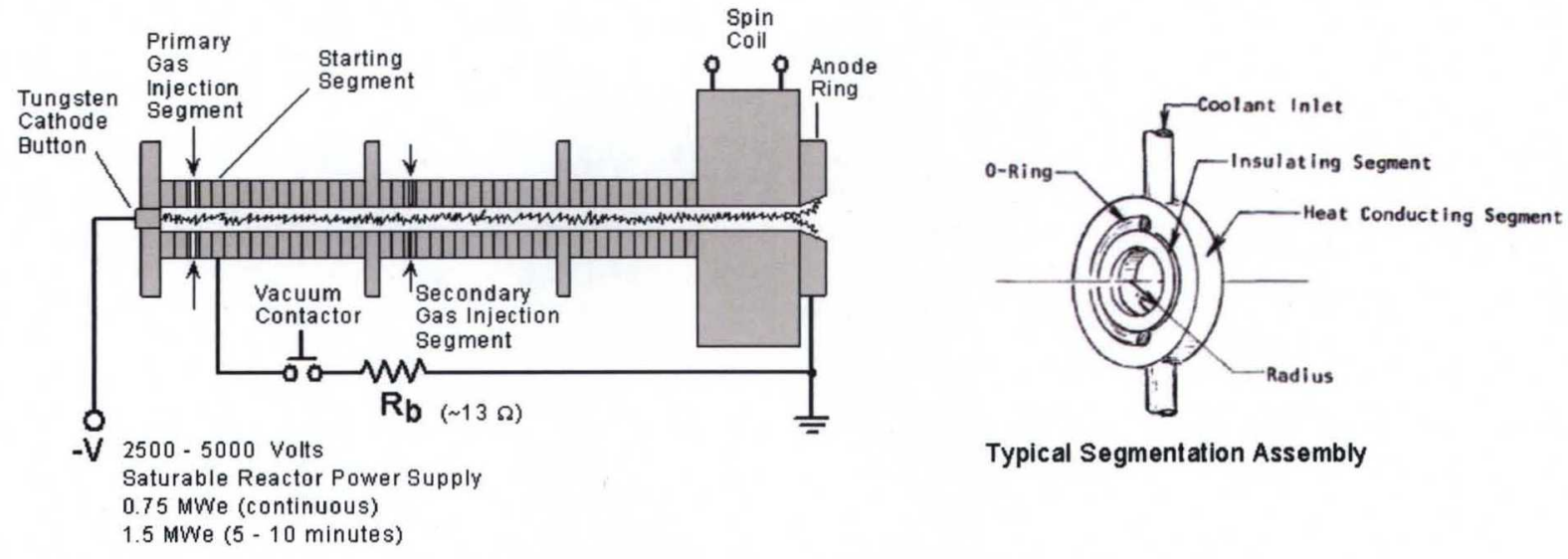

Typical Segmentation Assembly

Figure 3. Segmentation and assembly detail of the NASA MSFC 1-MW $\mathrm{H}_{\mathrm{e}}$ multi-gas arc-heater.

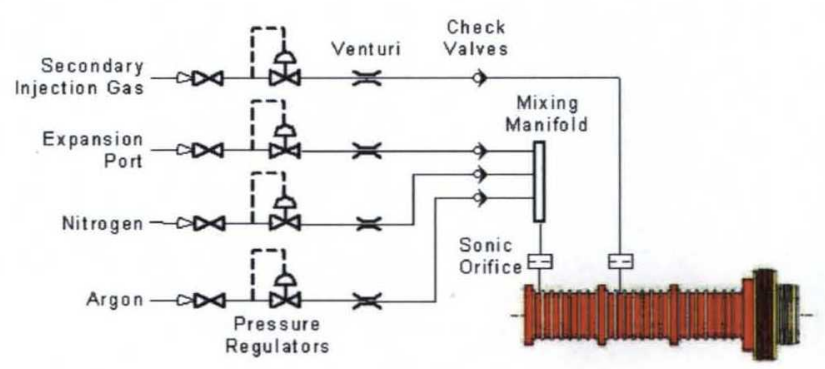

Gas Supply Schematic

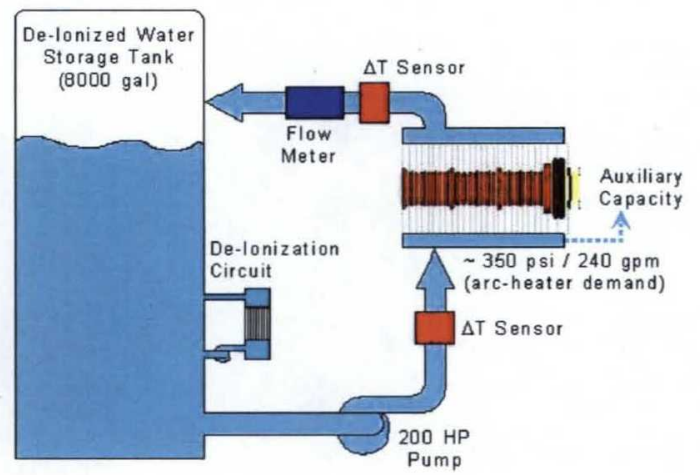

Cooling Loop / Calorimeter Schematic

Figure 4. Arc-heater facility schematics for gas supply and cooling loop / calorimeter subsystems.

an overall length of about 1 meter in the three-pack configuration shown. The working gas is injected tangentially through four 0.048-inch jets in a Primary Gas Injection (PGI) segment near the rear of the arc-heater, and a DC arc discharge is established between a tungsten cathode button in the rear sealing flange and a copper anode ring at the arc-heater exhaust. A magnetic spin coil is located around the anode ring to induce continuous rotation of the arc attachment point. Facility schematics for the gas supply and cooling loop / calorimeter subsystems are shown in Fig. 4.

In order to start the device at atmospheric chamber pressure, a modest flow of argon is first introduced into the arc-heater and an initial gas discharge is established between the cathode button and a starting segment, which is located just downstream of the PGI segment. The anode power lead is then automatically switched from the starting segment to the anode ring by opening a vacuum contactor, which establishes a stable arc down the full length of the arc-heater. At this point, argon flow can be replaced with the desired working gas and the system can be ramped to the desired operating state.

The arc-heater is energized by a saturable reactor DC power supply which can sustain a continuous operating power of $0.75-\mathrm{MW}_{\mathrm{e}}$ on an indefinite basis and can deliver an intermittent power burst of $1.5-\mathrm{MW}_{\mathrm{e}}$ for 5 to 10 minutes. This power supply can be configured in either parallel mode ( 2500 volts open circuit) or series mode (5000 volts open circuit) as needed to match the internal impedance characteristics of the gas discharge, and for high impedance hydrogen operation, the power supply was therefore placed in series mode configuration. Furthermore, the maximum electrical power input to the NTR reactor environments simulator was limited to no more than 750 $\mathrm{kW}_{\mathrm{e}}$ in order to fully replicate the long duration reactor burn times (1 to 2 hours) required for most exploration mission scenarios of interest. The achievable hydrogen flow rates over the desired temperature range were estimated using the NASA Chemical Equilibrium with Applications (CEA) code assuming various values for the electric-to-thermal efficiency. The results are summarized in Fig. 5 for 300,400 , and $500 \mathrm{~kW}_{\text {th }}$ of thermal input 
power for chamber pressures of 11,18 , and $35 \mathrm{~atm}$. Historical data on arc-heater performance indicated an expected efficiency in the range of 50 to 60 percent for these conditions, which implied a hydrogen flow rate of $7-10 \mathrm{~g} / \mathrm{s}$ over a temperature range of $2500-3500 \mathrm{~K}$. Pressure effects were found to have only a minor perturbative effect within this temperature range.

\section{B. Test Fixture Design and Analysis}

A modular water-cooled test fixture was designed in which small rod-shaped material specimens could be securely mounted and exposed to the arc-heated hydrogen flow through direct attachment to the arc-heater exhaust flange. The test fixture design also included optical access features for real-time pyrometer measurement of specimen surface temperature and for non-intrusive laser-based measurement of the hydrogen thermodynamic state. The baseline design specifications for the test fixture are summarized in Table 1.

A detailed mechanical design for the test fixture was developed based on these specifications, yielding the final layout shown in Fig. 6. The test fixture is essentially configured as a stack of water-cooled copper segments including an adaptor attachment to the arc-heater anode section and a converging nozzle section where the flow is throttled through a graphite nozzle with a tungsten throat insert. The mid-section contains features for insertion of a tungsten spider to hold small material specimens (1-inch long, $1 / 2$-inch diameter rods) and has four windowed ports for optical access. One port is canted to allow pyrometer measurements of specimen surface temperature during exposure. Two diametrically opposed ports allow for focusing of a laser excitation beam at a location just upstream of the specimen nose, and a fourth port is rotated $90^{\circ}$ out of this plane for capture of Raman scattering from diatomic hydrogen, which can be used to infer the rotational temperature and number density of molecular hydrogen.

Externally, the test fixture has a length of about 12 inches and a diameter of about 6 inches. Because all cooling water is drawn from a single 350-psig supply manifold, the water passages were sized to have the same pressure drop as the arc-heater segments in order to obtain proper flow rate splitting. This required the milling of $1 / 8$-inch passages into the copper segments, which were sealed with e-beam welded ring plates. Stress considerations for the 2.5-inch inner bore diameter required a 1/8-inch thickness between the water passages and the inner wall surface. These dimensions may be compared with 1/16-inch passages and 1/16-inch wall thicknesses for the arc-heater segments, which have a 1 -inch bore diameter.

Thermal hydraulic analyses were performed using an in-house three-dimensional computational fluid dynamics tool to assist in test fixture design and performance assessment. Multi-physics invoked in these analyses include turbulence, hydrogen dissociation, equilibrium thermodynamics, convective heat transfer, and radiation transport. The main goals of this supporting analysis was to quantify chamber wall heat flux and combined heat transport effects on specimen temperature so that the desired exposure conditions could be achieved during materials development tests.

Initially, we considered a basic design configuration in which there was no thermal barrier between the hot hydrogen flow and the copper wall. Detailed analyses of this configuration revealed the formation of intense vortices near the wall which raised the local heat flux beyond acceptable limits for the maximum specified operating conditions. Moreover, it was observed that radiation losses from the specimen to the cold copper wall through the highly transparent hydrogen were draining energy from the specimen and significantly lowering the surface temperature below the gas temperature. To circumvent these design problems, a 0.060 -inch thick $\mathrm{W} / 5 \% \mathrm{Re}$ heat shield was inserted with a 0.125 -inch gap between the shield and the copper wall, as shown in the layout drawing of 


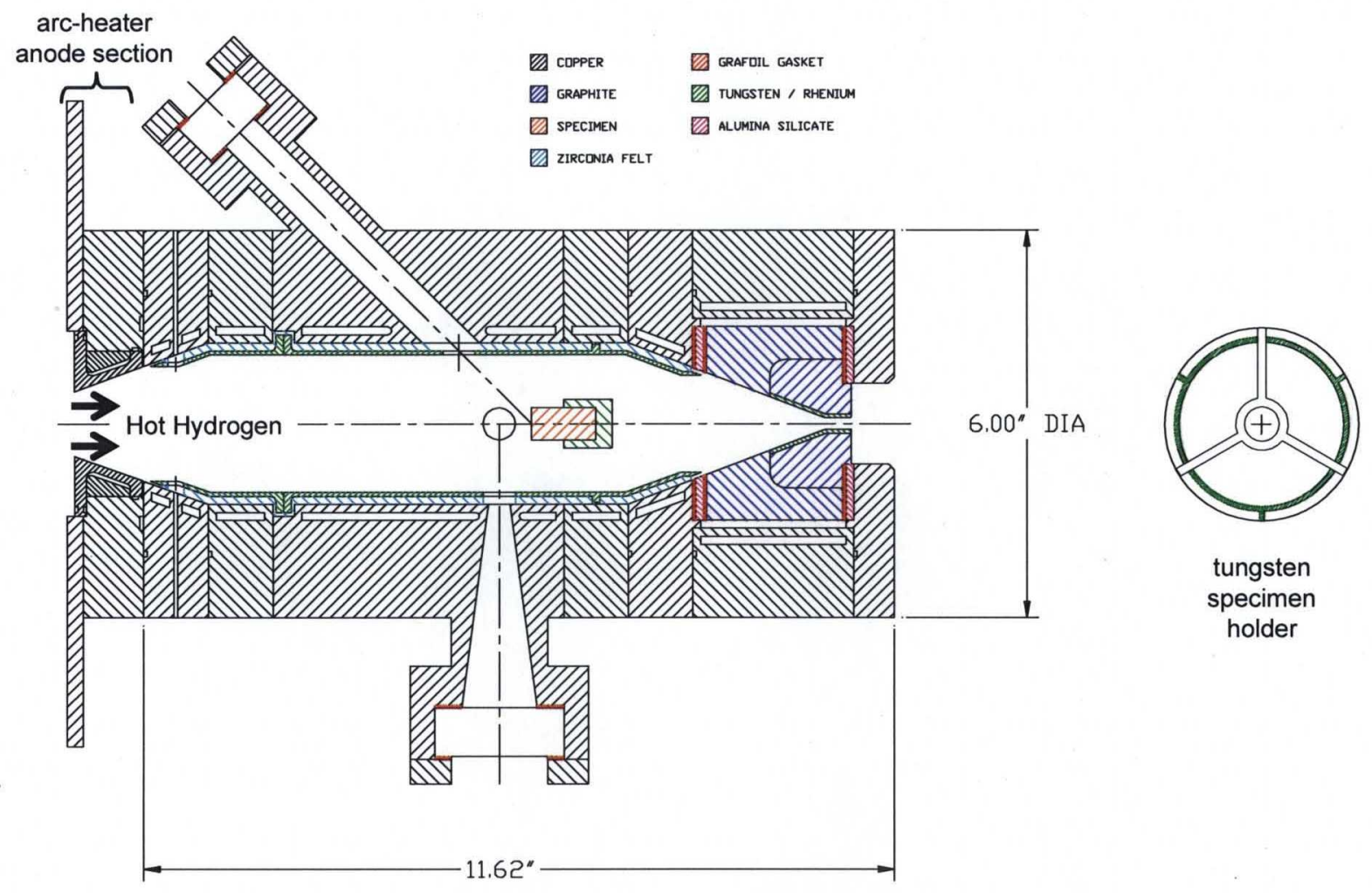

Figure 6. Test fixture layout drawing for the hot hydrogen nuclear thermal environments simulator.

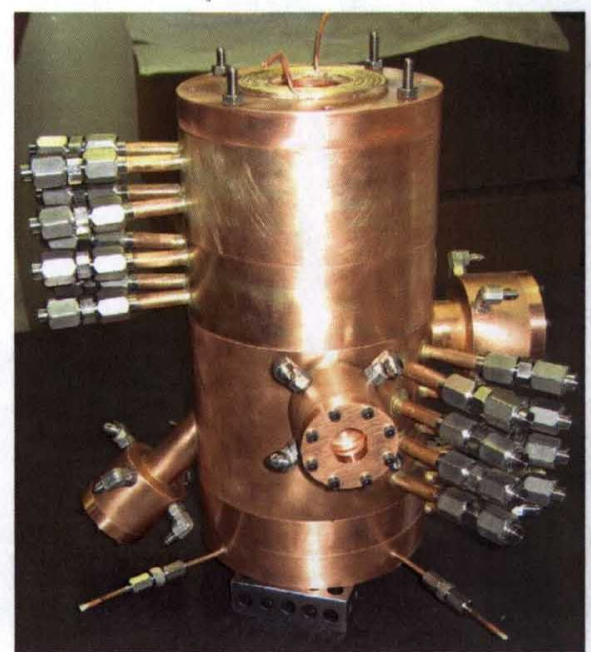

Test Fixture Assembly

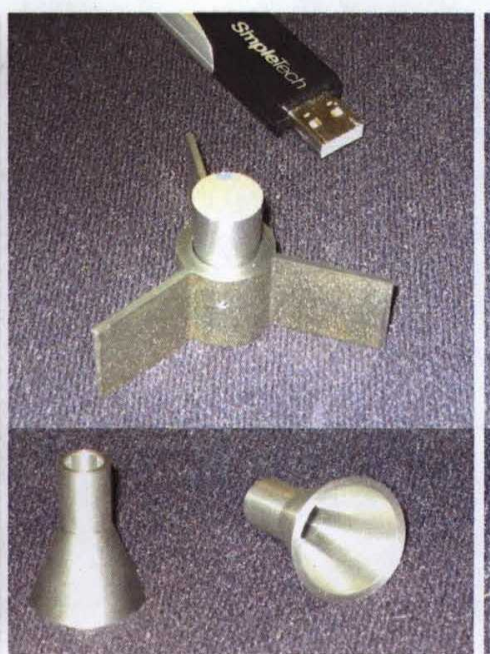

Specimen Holder \& Nozzle Insert

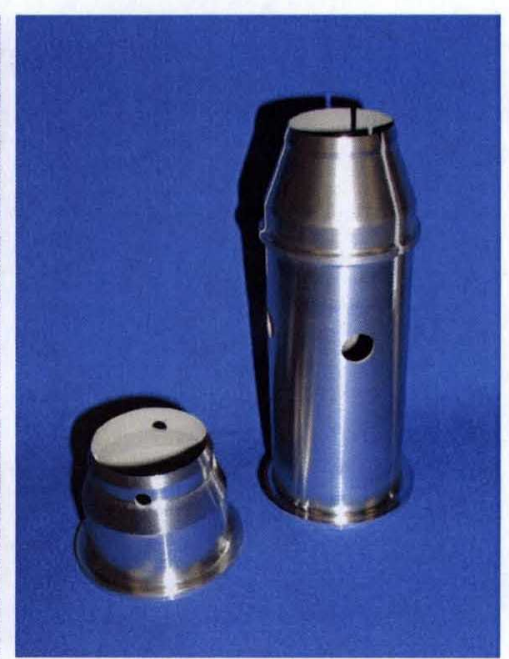

W/5\%Re Heat Shield

Figure 7. Photographs of fabricated test fixture hardware and refractory metal alloy components.

Fig. 6. A ring-shaped dam was also incorporated on the outer surface of the shield to prevent seepage of hot hydrogen flow through the backside gap. Detailed analyses of this configuration showed that the high heat flux vortices were completely isolated on the inner surface of the shield and revealed that the wall heat flux could be kept below an acceptable $500 \mathrm{~W} / \mathrm{cm}^{2}$ at the maximum design operating temperature.

Thermal and stress design analyses were performed in-house, and the final working drawings were reviewed and approved prior to letting of contracts for component fabrication. Photographs of fabricated test fixture hardware and refractory metal alloy components are shown in Fig. 7. The tungsten specimen holder was machined from a 
tungsten block using Electrical Discharge Machining (EDM) methods and is shown with a W-carbide specimen, which is secured to the holder by two tungsten pins. These pins are slipped through holes in the holder and engage notches in the specimen as a means of locking it in place. The tungsten nozzle insert was also machined using EDM methods. The large diameter W/5\%Re heat shield was formed as a net shaped part using a Vacuum Plasma Spray (VPS) technique and the outer surface was ground finished. This particular part is quite unique in terms of material, size, and shape and represents a fundamental advancement in VPS fabrication capability.

\section{Arc-Heater Performance Characterization}

As the various test fixture pieces and components were being fabricated, parallel project efforts were directed at establishment of basic arc-heater operational capability for hydrogen. This included installation of a supply line with a flow meter and regulator sized for delivery of $10 \mathrm{~g} / \mathrm{s}$ of gaseous hydrogen from a high-pressure, high-capacity tube trailer. Flow rate estimations indicated that a fully charged tube trailer would have sufficient capacity for more than 1-hour of continuous arc-heater operation. As part of this general activation activity, it was also necessary to refurbish and assemble various facility components, establish and implement operational procedures, and conduct thorough safety/hazard assessments.

Baseline arc-heater performance capability was established by attaching a sacrificial graphite nozzle assembly directly to the arc-heater anode flange. The sacrificial nozzle was machined from high-density graphite with a throat diameter matching the final test fixture design specifications so that the proper flow rate and chamber pressure would be produced at the specified mass flow rate and input power settings. This approach provided a reliable method for accurate performance characterization while test fixture hardware was in fabrication.

An arc-heater starting sequence was successfully established for hydrogen operation, and we then embarked on a series of performance mapping tests to empirically correlate operational parameters with the controllable input settings. In this case, the two controllable input parameters were the applied arc current and the mass flow rate, as established by the supply pressure to the PGI jets. The applied voltage of the power supply was uniquely determined by the arc plasma impedance for the applied current setting.

After a few exploratory tests, we were able to verify steady-state operational conditions could be reliably established within 20 seconds of arc initiation, as may be seen from the start-up transients for a typical 60 -second hydrogen run in Fig. 8. Therefore, we were able to generate steady-state performance tests with run times restricted to the range of $30-60$ seconds.

During these test, we recorded basic operating parameters such as current, voltage, chamber pressure, hydrogen mass flow rate, cooling water temperature rise, and cooling water flow rate from which we could infer system power balance and electrical-to-thermal conversion efficiency. The thermal input power, for example, was defined as the difference between the electrical input power and the heat loss power to the cooling water, and this parameter was then used to infer the efficiency. Given the thermal power input and the known throat size, we could also estimate the total enthalpy/temperature of the hydrogen in the chamber by running a rocket calculation using the NASA CEA code. The results obtained using this particular approach appeared to be very reliable since the predicted chamber pressure differed from the measured value by less than 1 percent in all cases. Although the gas is clearly in a highly non-equilibrium state within the instantaneous arc region, the volume of this region is small in comparison to the bulk flow and the rapidly fluctuating arc structure insures intense mixing of the two regions.

About 80 runs were successfully completed during the performance characterization test program, which yielded a database sufficiently populated to support the development of a reliable operating map. The integrated run times for hydrogen operation exceeded 40 minutes, and the uncoated graphite throat eroded from 0.273 " $\varnothing$ to $0.279 " \varnothing$ over that entire period. It should be

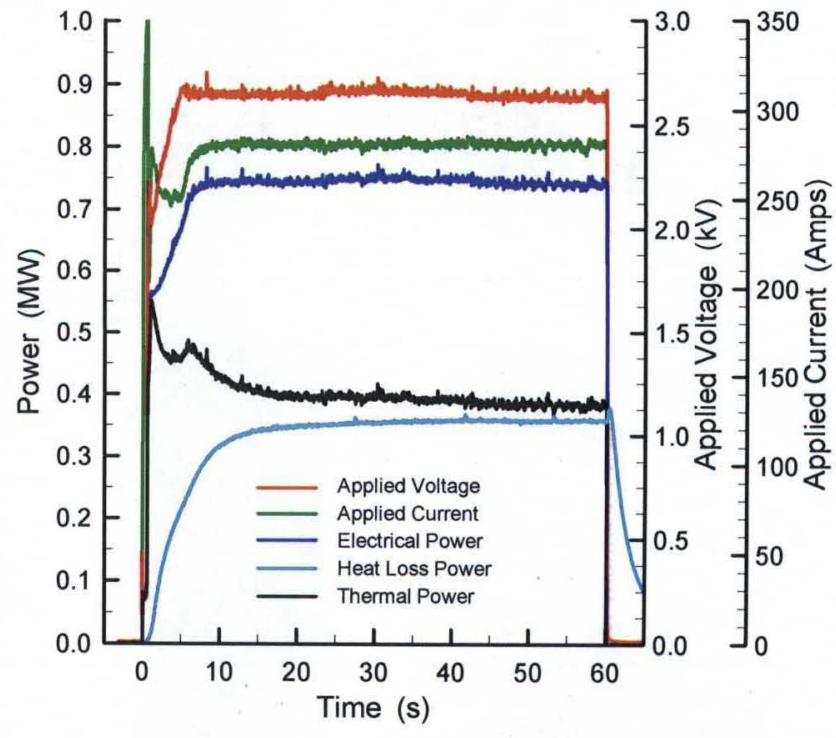

Figure 8. Start-up transients and establishment of steadystate operating conditions during a typical arc-heater performance mapping test. 


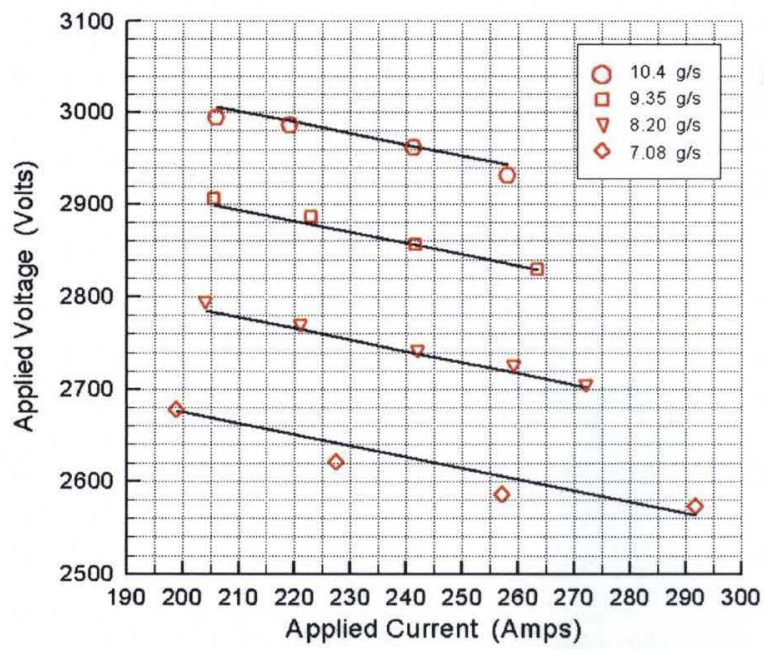

Figure 9. Arc-heater load lines at various hydrogen flow rates.

pointed out that graphite erosion was least severe during the initial 30 seconds of operation and significantly more severe following attainment of the fully thermalized state. The hot hydrogen plume remained essentially transparent during the initial warm-up stage, but after about 30 seconds of operation the graphite nozzle finally attained thermal steady state and soot formation could thereafter be observed as a result of methane afterburning.

The operating load lines for hydrogen operation are summarized for four different flow rates in Fig. 9. For applied currents between 200 and 300 amps, the load impedance was in the range of 2500 to 3000 volts as the hydrogen flow rate was varied between 7.0 and $10.4 \mathrm{~g} / \mathrm{s}$. Applied currents less than about 200 amps yielded unstable arcs leading to blowout. The highest current point for each flow rate was governed by the maximum continuous power limit of the system $\left(750 \mathrm{~kW}_{\mathrm{e}}\right)$. Within this current range, arc-heater operation with hydrogen was found to be stable and repeatable even though EMI was quite intense. The load lines were found to be very linear over the operational range of interest with a drop in load impedance of about 100 volts when the flow rate was decreased by $1 \mathrm{~g} / \mathrm{s}$. This is intuitively understandable since a decrease in flow rate implies a corresponding reduction in chamber pressure for a fixed nozzle throat size, which leads to a lower plasma resistance at the same current level.

The arc-heater efficiency characteristics for hydrogen flow rates between 7.0 and $10.4 \mathrm{~g} / \mathrm{s}$ are summarized in Fig. 10 as a function of applied electrical power between 500 and $750 \mathrm{~kW}_{\mathrm{e}}$. It was observed that the inferred efficiencies could be correlated independently of flow rate with no more than a 1 percent deviation from the linear fit, as indicated by the dashed lines on Fig. 10. Generally speaking, the efficiency fell from about $57 \%$ at $550 \mathrm{~kW}_{\mathrm{e}}$ to approximately $54 \%$ at $750 \mathrm{~kW}_{\mathrm{e}}$. These results were based on a thermal power balance assuming that the globally measured heat loss power for the device accounted for all losses associated with the electrical-to-thermal energy conversion process.

The resulting arc-heater performance map is shown in Fig. 11 where the inferred chamber temperature has been correlated as a function of applied current and hydrogen mass flow rate. Symbols indicate data points used to construct the map, and the chamber temperature at each point was estimated by using the inferred thermal input power to define a pseudo heat of combustion for a NASA CEA based rocket calculation. Bounds on the operating range are indicated by solid lines on the map. The upper bound on applied current is determined by the maximum 
continuous power limit of the power supply $\left(750 \mathrm{~kW}_{\mathrm{e}}\right)$. The lower bound on applied current, on the other hand, is defined by arc stability considerations. That is, for currents below approximately $200 \mathrm{amps}$, the current density becomes too low to stabilize the arc and the discharge cannot be sustained within the flow rate range of interest. The upper bound on hydrogen mass flow rate is governed by basic facility throughput limitations, as established to meet test fixture design specifications. Within this bounded region, the accessible hydrogen temperature ranges from 2400 to $3100 \mathrm{~K}$, as needed to simulate NTR reactor environments. If less stressful start-up and shut-down transients are desired to avoid thermal shocking of material specimens, the temperature may be temporarily forced lower in the test fixture by introducing additional cold gas through four gas injection ports in the first expansion ring, as indicated in the layout of Fig. 6.

\section{Long Duration Testing}

The critical step of the project, following establishment of the hydrogen operating map and fabrication of the test fixture hardware, was full-up assembly and execution of basic capability tests. These tests were principally intended to demonstrate long duration hot hydrogen operation, validate hardware, expose any major design flaws, and evaluate a pyrometer diagnostic for real-time monitoring of specimen surface temperature. In order to make these demonstration tests as realistic and relevant as possible and to reinforce the usefulness and value of non-nuclear reactor environments simulation for hydrogen compatibility testing, we also installed and exposed a specially fabricated ceramic metal matrix composite (i.e., CERMET) surrogate fuel specimen.

\section{A. CERMET Specimen}

A significant component of recent nuclear thermal propulsion R\&D efforts at NASA MSFC was largely directed at materials related technical issues, and one of the principal focal points of these efforts was the development of fabrication techniques for high-temperature CERMET fuels, such as W-Re/UO2 and W-Re/UN, and carbide fuels such as $(\mathrm{U}, \mathrm{Zr}) \mathrm{C}$ and $(\mathrm{U}, \mathrm{Zr}, \mathrm{X}) \mathrm{C}$. Of considerable special interest was $\mathrm{W}$ and $\mathrm{W}$ - $\mathrm{Re}$ based CERMET materials containing 20-60 volume percent $\mathrm{UN}$ or $\mathrm{UO}_{2}$ fuel particles.

Rather than proceeding directly to uranium containing samples, however, conventional processing techniques including press/sinter and Cold/Hot Isostatic Pressing (CIP/HIP) were employed to first fabricate samples containing surrogate fuel particles such as $\mathrm{ZrN}$ and $\mathrm{HfN}$. With this approach it was possible to evaluate processing parameters such as particle size, composition, fuel loading, initial consolidation techniques, and sintering and CIP/HIP conditions while also producing specimens that could be exposed to hot hydrogen environments as part of our capability demonstration tests. For our purpose, $\mathrm{W}-5 \% \mathrm{Re} / 40 \% \mathrm{HfN}$ surrogate fuel specimens were fabricated using a standard $\mathrm{HIP} /$ sintering procedure. $\mathrm{HfN}$ was chosen as the surrogate since it provided the best CTE match and density. First, high purity elemental $\mathrm{W}, \mathrm{Re}$, and $\mathrm{HfN}$ powders were blended in a Turbula mixer, and this blended material was then hot isostatically pressed and sintered in billets from which the test specimens were cut into the desired shape and size using a wire EDM technique.

Before insertion into the tungsten holder, which had a measured inside diameter of $0.505^{\prime \prime}$, the material specimen was ground down to $0.480^{\prime \prime} \varnothing$ and a parting agent was applied to avoid seizing effects and facilitate post test disassembly. The parting agent consisted of Type HfK-15 Hafnia Cloth (Zircar Zirconia, Inc.) layered onto the specimen with a paste of 904 Zirconia Ultra High-Temperature Ceramic Adhesive (Cotronics Corporation). This layered parting agent was applied with enough thickness to obtain a snug fit between the specimen and the holder. The securing pins were also treated with the same parting agent to facilitate post-test removal. A photograph of the specimen, with parting agent applied, is shown in Fig. 13 prior to assembly.

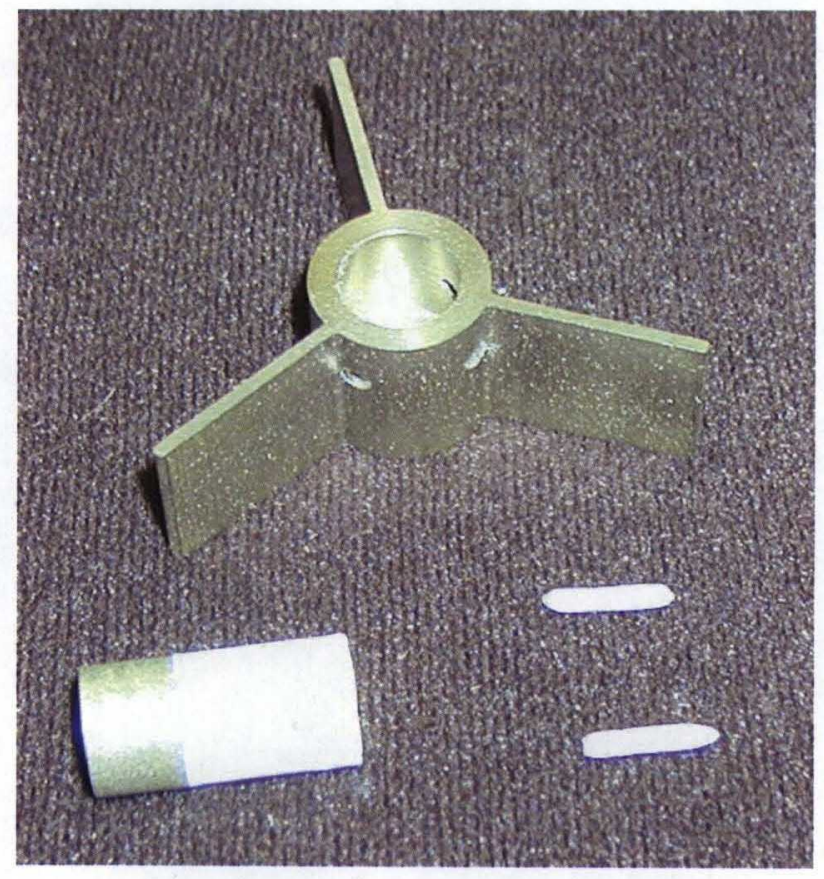

Figure 13. CERMET specimen with parting agent. 


\section{B. Pyrometry}

Due to the dominance of radiant transport in high temperature environments and the known transparency of hydrogen, it would be very difficult to reliably infer specimen temperature without undertaking complicated conjugate heat transfer calculations, and a direct measurement approach is preferred. Thus, provisions were incorporated into the test fixture design which would permit monitoring of the specimen surface temperature using a commercially available optical pyrometer (Mikron Model MI-S140X). This particular model uses a single color bandpass at $677 \mathrm{~nm}$ with adjustable focal length from 19 to $42 \mathrm{~cm}$ and has a laser sighting mechanism for alignment. The temperature range is 1373 to $3773 \mathrm{~K}$. In the proposed configuration, temperature measurement requires independent knowledge of the spectral emissivity $\varepsilon(\lambda, T)$ at the target wavelength, but due to the strong temperature dependence of thermal radiance, the measurement is not very sensitive to this requirement. At most, the fractional temperature error is only 0.165 of the fractional emissivity uncertainty. Given the emissivity, the manufacturer specifies an accuracy of $0.5 \%$ for this instrument.

\section{Test Fixture Assembly}

Prior to field mounting, the modular test fixture was carefully pre-assembled on a simple workbench saddle structure. The basic assembly procedure was to begin with the first segment, which mates directly to the arc-heater anode section, and sequentially attach additional segments along with the appropriate internal parts using four full length tie-rods. Because the tie-rod pass through holes were designed with counter bore recesses, it was possible to securely fasten each additional segment to the preceding segment and to build-up the full length assembly step-bystep. Furthermore, each segment was designed with a $1 / 8$-inch o-ring groove to provide a seal and prevent hot gas leakage at the surface interfaces.

To further reduce wall heat flux and minimize cooling losses, the two-piece heat shield was wrapped with Type ZYF-50 Zirconia Felt (Zircar Zirconia, Inc.) and bonded to the outer surface using 904 Zirconia Ultra High-Temperature Ceramic Adhesive (Cotronics Corporation). A design issue of additional concern was the potential for thermal creep and possible closure of the specimen mounting slots in the rear half of the heat shield. At sufficiently high temperature, the tungsten based material becomes ductile and it was recognized that thermal gradients in the heat shield could lead to closure of these slots making it impossible to remove the specimen holder once the material has re-cooled to a non-ductile state. To prevent this from occurring, separator pins were machined from tungsten rods and inserted into each slot using ceramic adhesive. Photographs of the mounted specimen and the heat shield with attached slot spacers are shown in Figs. 14 and 15.

Upon completion of bench assembly, the test fixture was mounted to the arc-heater using an aluminum saddle support structure, as shown in Fig. 16 , and cooling water and nitrogen purge lines were attached. The cooling water was diverted directly from the $350 \mathrm{psig}$ inlet manifold and returned to the outlet manifold so that the calorimeter measurements would account for additional heat loss in the test fixture. Nitrogen was supplied to the secondary injection ports in order to provide dilution flow capability and to minimize thermal shocking effects during start-up. The dilution flow rate was measured with a venturi and regulated through a choked orifice. Nitrogen purge flow was also supplied and metered to the window ports using choked orifices, and the pyrometer was fixed mounted as shown in Fig. 16.

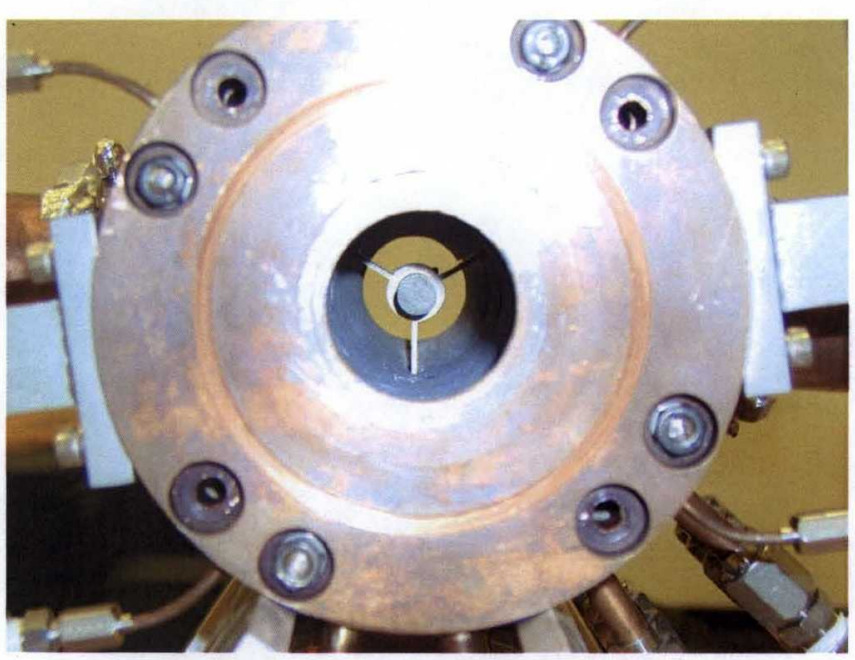

Figure 14. Internally mounted specimen and holder.

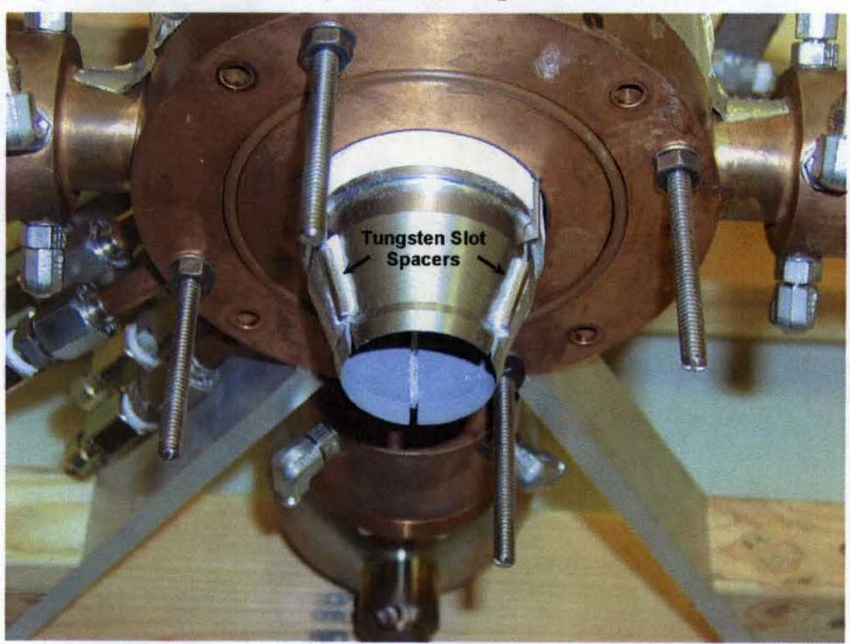

Figure 15. Mounted heat shield with W slot spacers

10

American Institute of Aeronautics and Astronautics 


\section{Long Duration Testing}

The overriding objective at this stage of the project was to demonstrate a reliable testing capability for long duration hot hydrogen exposure of nuclear reactor material specimens. This necessitated the ability to ramp and hold arc-heater power level, primary flow rate, and dilution flow rate and to maintain thermally stable operating conditions over a time interval representative of a nuclear thermal rocket engine burn. Secondary aspects of this capability demonstration test included validation of hardware, exposure of design flaws, and critical evaluation of our realtime pyrometery diagnostic.

As an initial demonstration, it was decided to attempt a $\mathbf{3 0}$ minute duration test at the lower end of the established operational temperature range. Specifically, the targeted on-point test condition was $10.5 \mathrm{~g} / \mathrm{s}$ hydrogen with an arc column current of 235 amps. With reference to the performance map in Fig 12, we therefore anticipated a nominal gas temperature close to $2500 \mathrm{~K}$. From a technical perspective, it was felt that this particular state point would be thermally less stressful on the hardware for a first test yet would be energetic enough to effectively demonstrate practical testing capability. To reach the desired on-point state condition, the facility would first be started at 10.5 $\mathrm{g} / \mathrm{s}$ and $205 \mathrm{amps}$ with hydrogen dilution flow added through the secondary injection ports for cooling purposes. Once stable operation has been achieved, the arc column current would be linearly ramped to $235 \mathrm{amps}$ while the hydrogen dilution flow would be simultaneously ramped to zero. The entire start-up sequence was automated for completion within 1 minute.

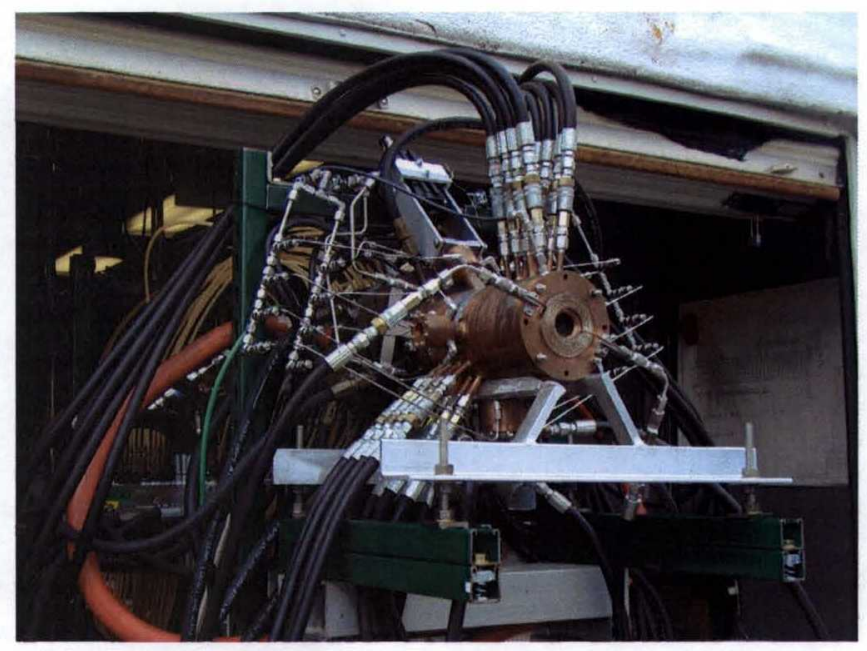

Figure 16. Fully assembled and mounted test fixture.

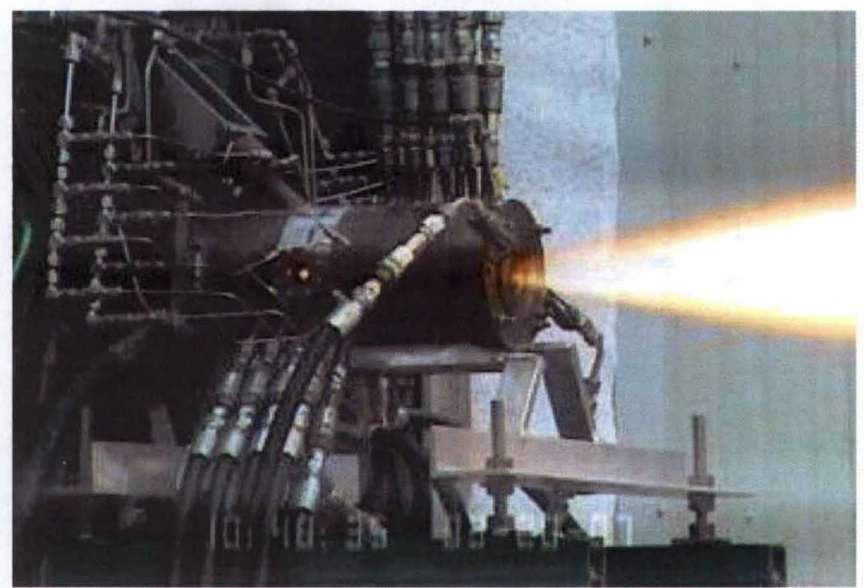

Figure 17. Long duration hot hydrogen testing image.

Subsequently, a long duration hot hydrogen firing was successfully concluded according to the preceding test plan. A steady state plume image extracted from a video recording of this firing is shown in Fig. 17. Following the initial start-up/ramp transient, the arc-heater facility exhibited excellent on-point stability characteristics and the monitored operational parameters displayed little or no drift/fluctuations. The total run time for this particular test was a little more than $26 \mathrm{~min}$. Applying the measured current and hydrogen mass flow rate $(10.3 \mathrm{~g} / \mathrm{s})$ to the hydrogen performance map of Fig. 12, we deduce an arc-heater efficiency of $54.2 \%$, which yields a hydrogen enthalpy of $36.5 \mathrm{~J} / \mathrm{g}(72.9 \mathrm{~kJ} / \mathrm{g}$-mole) at the test fixture entrance. Using these results in combination with the measured chamber pressure (148.7 psig) as input to the NASA CEA code yields a hydrogen static temperature of $2516 \mathrm{~K}$ at the test fixture inlet.

Time-averaged operating parameters for the entire experimental apparatus, which considers the arc-heater and the test fixture as a unit, are summarized in Table 2. Note that the hydrogen mass flow rate is higher and the thermal efficiency lower due to window purge gas and secondary cooling losses in the test fixture assembly. As a self-consistency check, we also carried out a NASA CEA rocket calculation using the steadystate operating parameters of the full experimental unit as chamber input conditions. This yielded a predicted hydrogen flow rate of $11.24 \mathrm{~g} / \mathrm{s}$, which is in very close agreement with the measured value of $11.1 \mathrm{~g} / \mathrm{s}$.

Table 2. Time-Averaged Parameters

\begin{tabular}{ll}
\hline \hline$P_{\text {electric }}$ & $693 \mathrm{~kW}$ \\
$Q_{\text {loss }}$ & $345 \mathrm{~kW}$ \\
$Q_{\text {net }}$ & $348 \mathrm{~kW}$ \\
$\eta=Q_{\text {net }} / P_{\text {electric }}$ & $50.2 \%$ \\
$\dot{m}_{\text {hydrogen }}$ & $11.1 \mathrm{~g} / \mathrm{s}$ \\
$p_{\text {chamber }}$ & $148.7 \mathrm{psig}$ \\
\hline \hline
\end{tabular}


It was inferred, from the calculated equilibrium static temperature at the arc-heater exit, that the hydrogen temperature in the region of the specimen would be quite close to $2500 \mathrm{~K}$ and that the surface temperature should be considerably lower due to radiation heat loss to the wall. A time trace of the inferred specimen surface temperature, as derived from the pyrometer signal, is shown in Fig. 18 where the emissivity of the $\mathrm{W}-5 \% \mathrm{Re} / 40 \% \mathrm{HfN}$ surrogate fuel was assumed to be $\varepsilon \approx 0.5$, which is representative of pure tungsten. This measurement implied a mean surface temperature of $\sim 2440 \mathrm{~K}$ during the steady state portion of the test. Intuitively, however, we shouldn't expect the specimen temperature to equal the gas temperature in a regime dominated by radiative heat transfer. The most likely culprit for this discrepancy is inaccuracy in the emissivity, a quantity which is extremely difficult to measure and verify at such extreme temperatures.

\section{E. Observations and Lessons Learned}

In general, the test fixture hardware held-up well and no serious design flaws were discovered. From a thermal perspective, the test demonstrated significant design integrity in that the cooling loop readily handled the high heat flux conditions and was able to absorb and remove heat at a rate sufficient to keep hot side wall temperatures well below practical design limits. Clearly, the $\mathrm{W} / 5 \% \mathrm{Re}$ heat shield with backside $\mathrm{Zr}$ blanket considerably reduced overall heat losses, and there is every reason to believe that this design can perform satisfactorily up to the original $3500 \mathrm{~K}$ specification requirement.

At the conclusion of the long duration test, the CERMET specimen was removed and the apparatus was completely disassembled for detailed inspection. During this disassembly process, it was confirmed that the tungsten slot spacers functioned as desired and prevented any undesirable closure that could have blocked removal of the specimen. In addition, the water cooled copper segments were essentially pristine and no degradation of any kind could be observed. Post test inspection photographs of the heat shield, graphite nozzle with tungsten insert, and CERMET specimen are shown in Fig. 19.

Inspection of the heat shield, following removal of the backside blanket of $\mathrm{Zr}$ felt, revealed no major flaws. Some discolorization of the external surface could be observed, but this was associated with the ceramic adhesive used to attach the insulation blanket and had no bearing on design functionality. Of more significant concern was the discovery of a small crack in the flange of the downstream heat shield piece. Most likely, this crack occurred due to thermal stresses induced by a strong temperature gradient between the hot inner surface and the out edge of the flange, which was in direct contact with the cold copper wall. The fear is that repeated thermal cycling will lead to crack growth and ultimately complete breakage of the part. For long term utilization of the apparatus, it will probably therefore be necessary to redesign the heat shield to minimize thermal stresses as well as make it simpler and cheaper to fabricate. Our current thoughts point toward a revised design concept based on multiple layers of thin tungsten sheets and ceramic felt insulation, however, we have not proceeded with this idea in any significant detail.

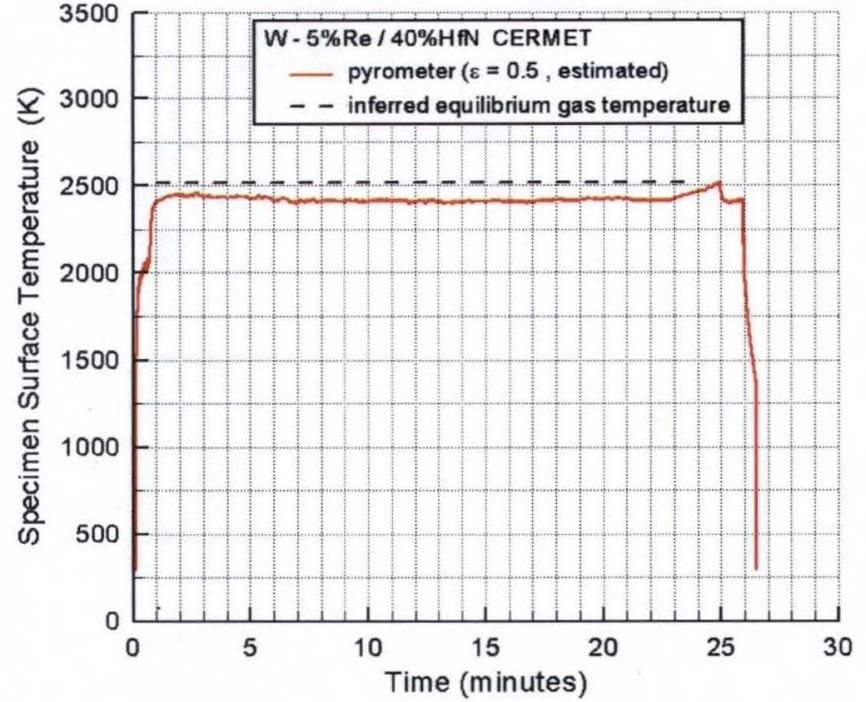

Figure 18. Time trace of specimen surface temperature.

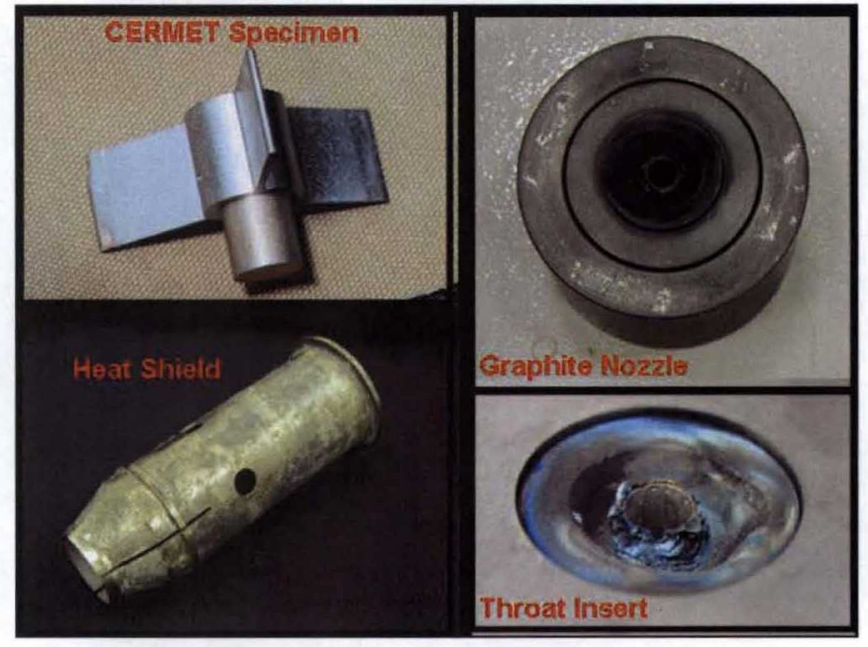

Figure 19. Post test inspection photographs. 
In general, the graphite nozzle and tungsten throat insert functioned well except for one minor design oversight. That is, air entrainment by the high velocity exhaust plume caused significant erosion of the exposed graphite as well as burning and pitting of the exposed tip of the tungsten insert, as may be observed in Fig 19. The unexposed upstream portion of the insert had no noticeable degradation. To avoid entrainment erosion, the nozzle assembly was redesigned such that nitrogen purge flow could be introduced through a 0.030 inch annular gap between the graphite nozzle plug and the rear clamping plate.

Inspection of the $\mathrm{W}-5 \% \mathrm{Re} / 40 \% \mathrm{HfN}$ following long duration exposure revealed a brownish discolorization in a granular like pattern at the specimen surface. Furthermore, the specimen swelled significant expanding from 0.500 -inch $\varnothing$

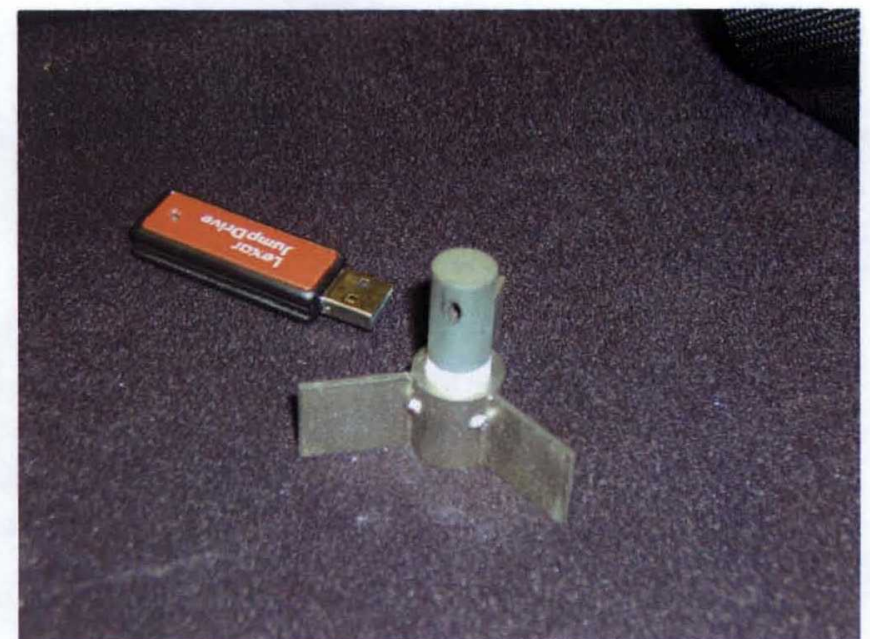

Figure 20. CERMET specimen with black body cavity. to 0.512 -inch $\varnothing$ (i.e., $2.4 \%$ ) during the test. Both the discolorization and swelling were attributed to hydrogen absorption and reaction with the $\mathrm{HfN}$, although this was not rigorously confirmed through analysis. A significant disadvantage of the current testing configuration is the lack of precision in the pyrometery measurements due to large uncertainties in the specimen emissivity, circumstances which will surely be re-encountered in any serious materials evaluation program, particularly in relation to innovative high temperature fuels. It was therefore decided to redesign the specimen with a small cavity into which the pyrometer could be focused thereby serving as a black body source for emissivity independent determination of temperature. This was accomplished by lengthening the specimen to $1 \frac{1}{2}$ inches and positioning the cavity such that its bottom surface corresponded to the surface focal plane of the original specimen. A photograph of a mounted $\mathrm{W}-5 \% \mathrm{Re} / 40 \% \mathrm{HfN}$ specimen based on this new design configuration is shown in Fig. 20 where the cavity was formed using a plunge EDM technique. The viability of this new approach will be critically evaluated in future long duration tests.

\section{Conclusion}

An arc-heated NTR environments simulator has been developed which can generate hyper-thermal convective conditions traceable to reactor core conditions for low-cost, non-irradiated hot hydrogen exposure and screening of candidate fuel and structural materials. A water-cooled copper test fixture was designed and fabricated for long duration exposure of $1 / 2$-inch diameter rod shaped material specimens in flowing hot hydrogen. The test fixture design also incorporates optical ports for real time optical pyrometry of specimen surface temperature and eventual implementation of a laser-based Raman spectroscopy diagnostic for measurement of molecular hydrogen rotational temperature and number density. Arc-heater performance mapping tests demonstrated an accessible temperature range of 2400 to $3100 \mathrm{~K}$ for hydrogen flow rates between 7 and $10.5 \mathrm{~g} / \mathrm{s}$.

As a capability demonstration test, a W-5\%Re/40\%HfN CERMET specimen was fabricated and exposed to 2500 $\mathrm{K}$ hydrogen gas for $\sim 26$ minutes. Post test inspections of the hardware confirmed overall basic design integrity although a few minor design modifications were suggested to improve robustness and reliability. Pyrometery measurements during the tests indicated a specimen surface temperature around $2440 \mathrm{~K}$, but this value is somewhat imprecise due to uncertainty in the material emissivity. To circumvent this deficiency in future tests, the configuration was altered to permit emissivity independent pyrometer measurements of a black body cavity machined into the specimen. Additional long duration capability demonstration tests are planned to extend the proven range of operation to $3000 \mathrm{~K}$ and to evaluate the back body cavity pyrometry technique.

\section{Acknowledgments}

Funding for this work was derived from the NASA MSFC IR\&D program, Focus Area Project 2005-80 entitled "Hot Hydrogen Materials and Component Development," and, in part, from funds associated with FY2006 Congressionally Directed Item Reference No. 53 for Advanced Propulsion Materials Research supporting the development of future space exploration capabilities. 


\section{References}

[1] D. R. Koenig, "Experiences Gained from the Space Nuclear Rocket Program (ROVER)," Los Alamos National Laboratory Report LA-10062-H, May 1986.

[2] F. P. Durham, "Nuclear Engine Definition Study Preliminary Report," Los Alamos National Laboratory Report LA-5044-MS, Vols. I - III, September 1972.

[3] J. D. Balcomb, "Nuclear Rocket Reference Data Summary," Los Alamos National Laboratory Report LA-5057MS, October 1972.

[4] F. P. Durham, "The Nuclear Rocket Program at Los Alamos," American Institute of Aeronautics and Astronautics Paper AIAA-1969-556, June 1969.

[5] W. H. Robbins and H. B. Finger, "Historical Perspective of the NERVA Nuclear Rocket Engine Technology Program," NASA CR-187154, July 1991.

[6] J. S. Clark (ed.), Proceedings of the NASA/DOE/DOD Nuclear Thermal Propulsion Workshop, NASA Lewis Research Center, Cleveland, OH, July 1990.

[7] J. R. Wetch, A. Ya. Goldin, A. A. Koroteev, A. D. Konopatov, V. A. Pavshook, N. N. Ponomarev-Stepnoy, and V. F. Semyonov, "Development of Nuclear Rocket Engines in the USSR," American Institute of Aeronautics and Astronautics Paper AIAA-1991-3648, September 1991.

[8] D. G. Pelaccio, M. S. El-Genk, and D. P. Butt, "Hydrogen Corrosion Considerations of Carbide Fuels for Nuclear Thermal Propulsion Applications," AIAA Journal of Propulsion and Power, Vol. 11, No. 6, 1995, pp. 1338-1348.

[9] M. S. El-Genk and D. G. Pelaccio (eds.), Proceedings of the Workshop on Hydrogen Corrosion in Nuclear Thermal Propulsion Reactors, 10th Symposium on Space Nuclear Power and Propulsion, Albuquerque, NM, 1994. 